\title{
System Dynamics Report of Telecom Industry in China
}

\author{
Jiayin Qi, Hua (Jones) Ai, Huaying Shu, and Zhanhong Xin \\ Economics and Management School, Beijing University of Posts and \\ Telecommunications, $10 \mathrm{Xi}$ Tu Cheng Road, Haidian District, Beijing, \\ China, 100876 \\ mailto:ssfqjy@263.net, \\ aidahere@tom.com, \\ shuhy@bupt.edu.cn, \\ xinzhanhong@263.net \\ WWW home page: http://www.sem.bupt.cn
}

\begin{abstract}
This article analyzes mobile carriers' competition strategies by using balanced scorecard and system dynamics. We use four indexes to evaluate the situations of 2 main Chinese telecom carriers like Internal Business Index, Financial index, Market \& Customer Index, as well as Innovation and Learning index. According to these four indexes and system methodology, a system dynamics model is provided, which has 4 subsystems and 80 variables. Taking the government influences into consideration as well as companies' strategies and the corresponding system simulations, we try to use system dynamics as a new enterprise computing analyzing method and give competition suggestions to the two mobile carriers.
\end{abstract}

\section{Introduction}

At present, Chinese telecom enterprises are facing the biggest challenges. $3 \mathrm{G}$ (the third generation of mobile communication technology) time is coming. Information technology is changing our world everyday. People concern how to combine internet with mobile technology. As the two mobile carriers in China, $A$ is the dominant carrier while B is the challenger. How could B operate well in the next step? What are the results if A reacts? What should the government do next?

System dynamics is a traditional simulation tool. It's broadly used in analyzing environment, social problems and so on $[1,5]$. Balanced scorecard was proposed by Kaplan and Norton and further developed by Berkman $[3,4,6]$ based on managerial

Please use the following format when citing this chapter:

Qi, Hua (Jones) Ai, J., Shu, H., Xin, Z., 2006, in International Federation for Information Processing, Volume 205, Rescarch and Practical Issues of Enterprise Information Systems, eds. Tjoa, A.M., Xu, L., Chaudhry, S., (Boston:Springer), pp.739-747. 
experiences of many superior companies. Developed in the early $1990 \mathrm{~s}$, this valuation methodology converts an organization's value drivers - such as customer service, innovation, operational efficiency, compensation [2] and financial performance-into a series of defined metrics.

Different from previous work, we resolve the problems by combining system dynamics with balanced scorecard and econometrics [7]. Searching the Securities and Derivatives Markets Quarterly Report of these 2 carriers of Hong Kong Exchanges Cooperate every half year, we extract data from 1999 to the first half of 2005 [8] and use a special software Vensim-PLE5.4c to establish a system dynamic model to simulate the operation situation of 2 carriers in China.

\section{System Dynamic Model for One Mobile Carrier}

This model (Fig.1) contains 4 subsystems according to the balanced scorecard. Considering the policy environment as surroundings, we evaluate indexes referring to EFE and IFE method [10]. The global telecommunication market environment is not considered.

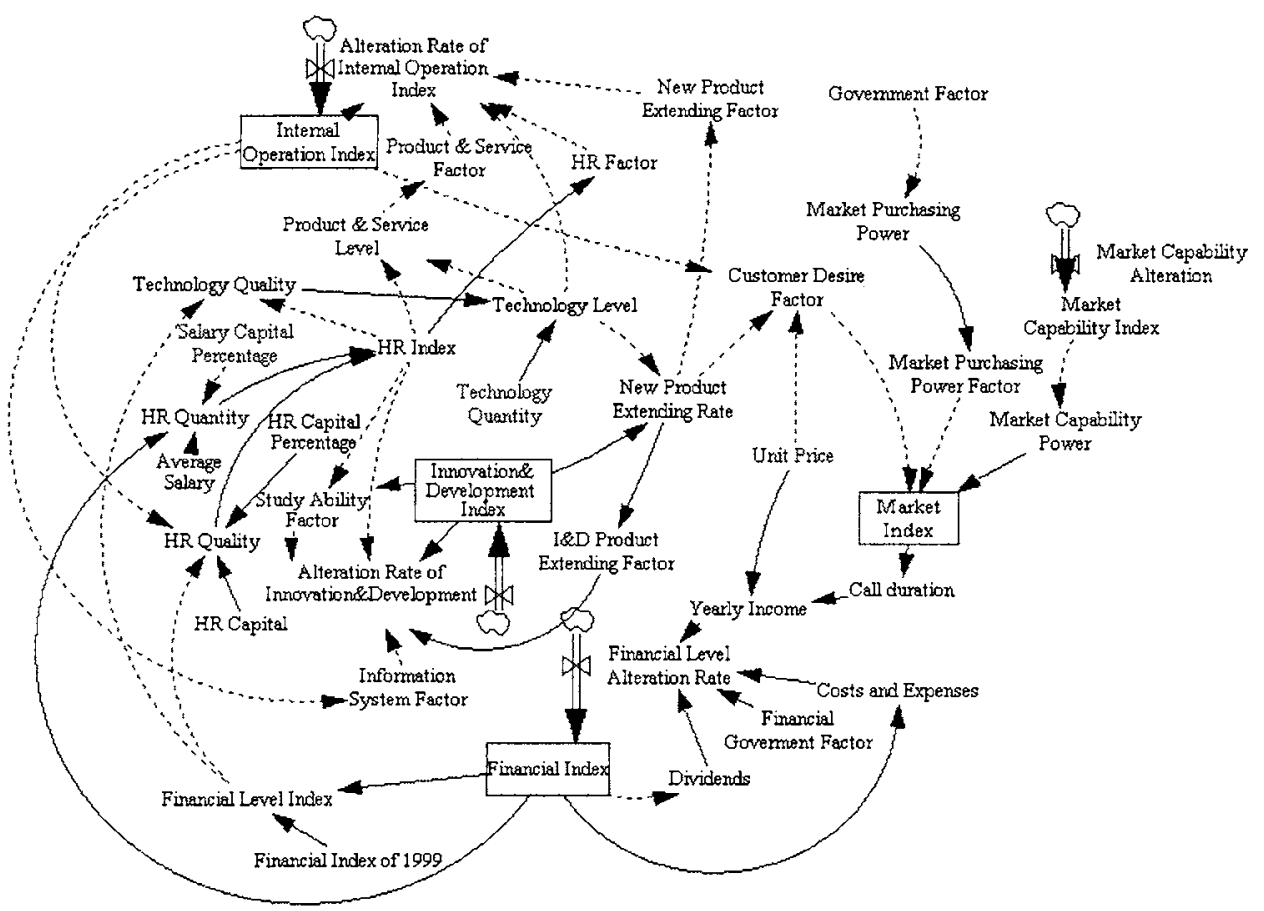

Fig. 1. Flows and stocks diagram of one operator $[9,11$, and 14]

Internal sub-system [Internal Operation Index (level variable), Alteration Rate of Internal Operation Index (rate variable)]. Human resource influences the core 
technology, and the stronger enterprise's competing ability is the higher core tech level will be. To simplify the problems and diagram, we use 2 rates to show the output of these 2 enterprises. Human Resource Level is affected by HR Efficiency Level and HR Quantity Level. Core Technology Level is affected by Core Technology Efficiency Level. Staff Efficiency is determined by Financial Level, Standard HR Investment Ratio and HR Investment Ratio.

Financial sub-system [Financial Index (level variable), Financial Alteration Rate (rate variable)]. Financial Alteration Rate is the synthesized function of 'Income', 'Expense and Cost ', 'Revenue', 'Dividend', and 'Government Factor'. Income is the product of unit price (income per minute for the telecom companies) and the call duration. Call duration is the conditional function of the Market Level. Here Government Factor is the auxiliary variable.

Market sub-system [Market \& Customer Index (level variable), Alteration Rate of Market \& Customer (rate variable)]: Alteration Rate of Market \& Customer is the synthesized function of 3 factors about Purchasing Power, Market Capability and Purchasing Desire.

Innovation and Development sub-system [Innovation and Development Index (level variable), Alteration Rate of Market \& Customer (rate variable)]. Innovation and development ability indicates an enterprise's ability and potential.

\section{Integrated System Dynamic Model for Two Mobile Carriers}

This model is for the competition situation simulation of the 2 companies (Fig. 2.).

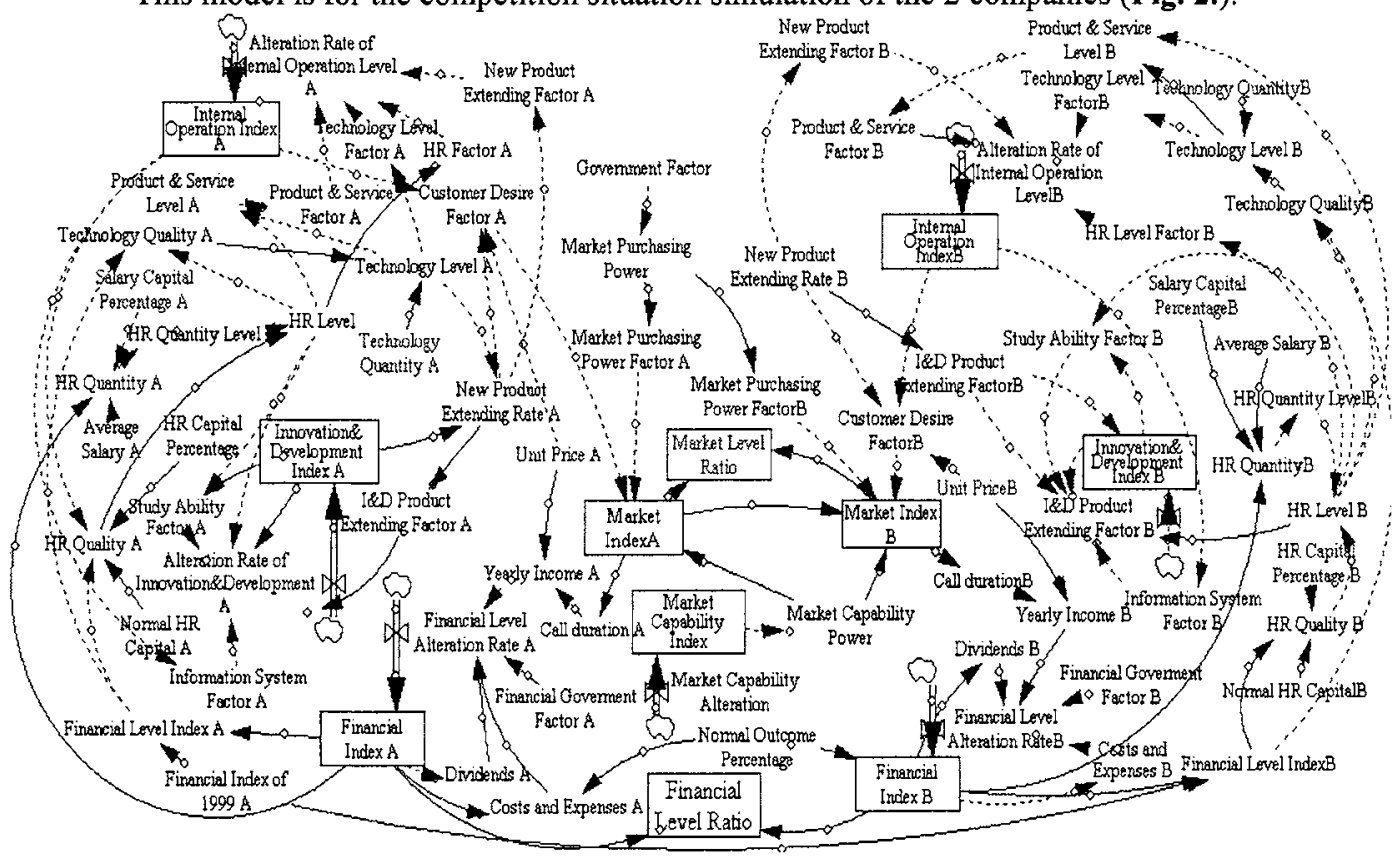


Fig. 2. The integrated system dynamic model

\section{Equations for Stocks and Flows of The Integrated System Dynamic Model}

Here we get the equations for the system simulation containing these 2 companies:

1. $d($ Internal Operation Level)/dt=Internal Operation Alteration Rate $=\mathbf{f} 1$ (Core Technology Factor, Human Resource Factor, Product \& Service Factor, New 2.Product Extending Factor); Internal Operation Level $\left.\right|_{t=1999}=4.3$;

3. $d($ Financial Level) $/ d t=$ Financial Level Alteration Rate $=f 2$ (Income, Expense and Cost, Revenue, Dividend, Government Factor);

4. Financial Level $\left.\right|_{t=1999}=65,733$;

5. d(Market\&Customer Level)/dt=Alteration Rate of Market\&Customer

=f3 (Purchasing Power Factor, Market Capability Factor, Purchasing Desire Factor);

6. Market\&Customer Level $\left.\right|_{\mathfrak{l}=1999}=5.5$

7. $\mathrm{d}($ Innovation\&Development Level)/dt=Innovation\&Development Alteration Rate

$=\mathrm{f} 4$ (Study Ability Factor * New Product Extending Factor* Information System Factor) +1)* Innovative\&Develop Level;

8. Innovation \& Development Level $\left.\right|_{\mathrm{t}=1999}=1$;

9. Financial Ratio = Financial Index A/ Financial Index B;

10. Market Index Ratio= Market Index A $/$ Market Index B;

As to the similarities between the systems of $\mathrm{A}$ and $\mathrm{B}$ we do not list the equations for $\mathrm{B}$ here.

The data sample is shown in Table1 in appendix.

OLS [12] parameter estimation;

$$
\begin{aligned}
& \mathrm{CRY}=\mathrm{u}+\beta_{1}{ }^{*} \mathrm{FY} ; \\
& \mathrm{CRL}=\mathrm{u}+\beta_{1}{ }^{*} \mathrm{FL} ;
\end{aligned}
$$

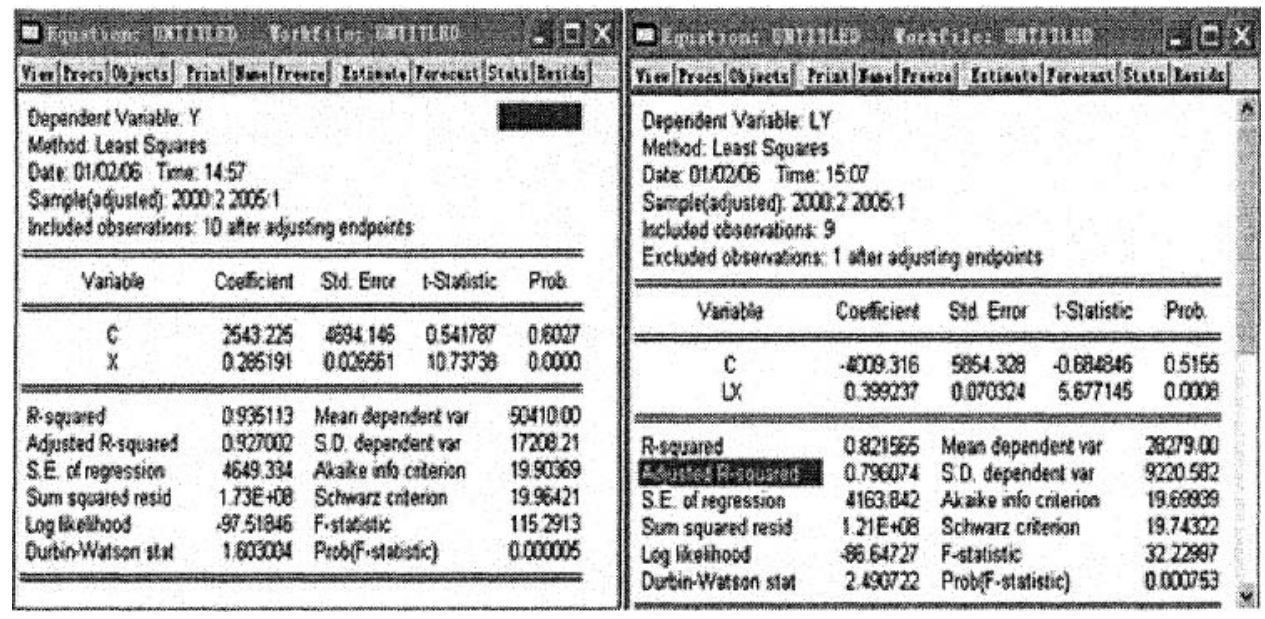


Fig. 3. Eviews output of the costs analyses

To process the data reliably and accurately, we use software Eviews. Take the conditional function of Net Assets, Expenses \& Costs for example: $\mathrm{CRY}=2543.225+0.285 \mathrm{FY}, \mathrm{F}=115.2913, \mathrm{DW}=1.518, \mathrm{r}^{2}=0.935$, interpret that only $6.5 \%$ could not be explained by sampling regression linearity with $93 \%$ of the total sum of squares of deviations qualifies. The sample regression line explains the sample point with a high goodness of fit (Fig. 3). It means the modeling may be in a fit format. Similarly, the correlation between Expenses\& Costs level and net assets of Firm B: CRL $=-4009.3+0.399 \mathrm{FL}$. (Low goodness of fit indicates the superior firm has more choices and is much more dependent)

Equations: $\mathrm{LS}=-2826.122+0.994 * \mathrm{LFI} ; \mathrm{YS}=-13872.408+0.633^{*} \mathrm{YFI}$

\section{Simulation Results}

\subsection{Carrier B:}

Because financial circumstance is the most important index for the operator and market is carriers' final goal, we pick graphs concentrating on these 2 sides. Fig. 4 illustrates the financial ratio and Fig. 5 describes the customer index's development in the next 5 years. (After B adopts the new strategy, keeping the total investment ratio at 1.2 and it improves the salary ratio and HR investment ratio to 1.25 .)

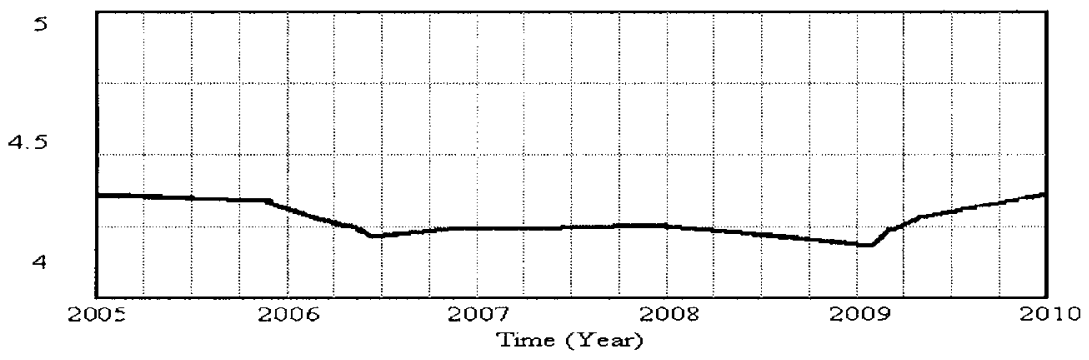

"IVI\&CR" : firial

Fig. 4. Financial situation of carrier B in 2005 2010(FR- Financial Index Ratio)

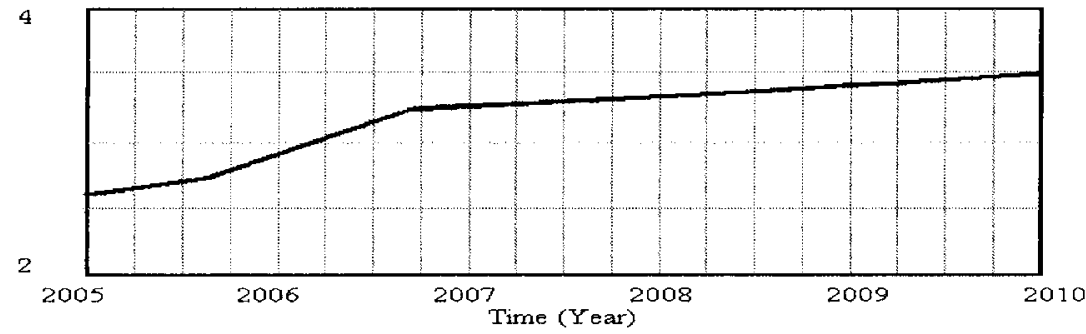

FR : fina1 
Fig. 5. If carrier $B$ takes the new strategic plan into application 2005 2010 (M\&CR-Market and Customer Ratio)

From the graphs, we could see the slopes are positive, which means the distance between $\mathrm{A}$ and $\mathrm{B}$ is always growing and the speed is slowing down, with financial index increasing to 3.5 and $M \&$ CR to 4.35 at the end of 2010 , (compare with FR 7.9 and M\&CR 9.2 in 2010 if $B$ do not adopt new strategic plans and the negative deposits lead to a negative circle). Originally A's net profit was 18 times of B's in 2005 and if $B$ adopts the strategic amendment that would be delayed to 2010 or later. In the next 5 years it would experience several fluctuations; nevertheless the overall slope is going down but still larger than 1 , indicating that B is still at the disadvantageous position. Here we could see the net asset ratio is much lower than that of net profit 2.26 in 2004. And that benefits B.

\subsection{Carrier A}

For carrier A, we compare carrier A's 2 situations whether A reacts after B changes its strategies or not. Market is the corporations' aim and also the factor we very concern.

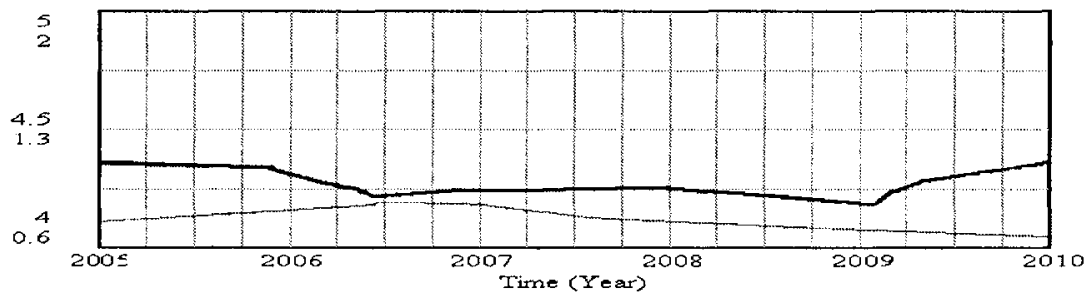

"MAsck" : final CPDR : final

(a)

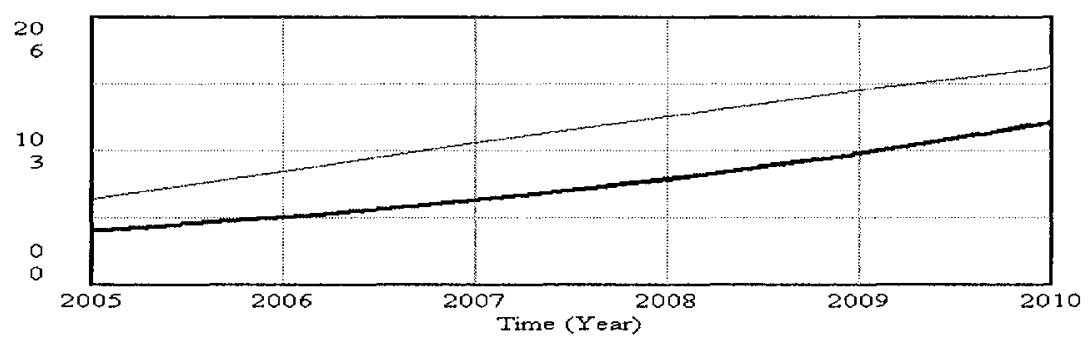

"M\&CR" : final

CPDR : final

(b) 
Fig. 6. Simulation for the next 5 years--A does noting (Fig. 6 (a)), and A reacts immediately after B (Fig. 6 (b)) when B works as in Fig. 5 (M\&CR is Market and Customer Ratio, CPDR is Customer Purchasing Desire Ratio)

We could see the financial ratio would keep on increasing from 4.35 to 12 in the next 5 years if $A$ reacts immediately after $B$ and the government does not interrupt with any anti-monopolization regulations. Among the top 500 companies, A ranks low in income but much higher in profit, which implies that the price of A is not very reasonable. So the structure of the price should be optimized and keep track with international level.

\section{Conclusions and Limitations}

Firstly carrier B could increase the investments and management efficiencies by improving human resource level and keep other level ratios to a certain degree simultaneously; To Concentrate investments in key areas including bonuses [16] and HR funds to maximize profits secondly; And to allege that they are aiming at becoming the second largest mobile carrier in China's Mobile Industry to distract competitions threats step by step [15].

Carrier A could firstly segment the market and emphasize differences. Second, it should develop products of lower price level and consider showing competition threats, improving the innovation and customer service investment, and finally individuating products to make them more different and remarkable so as to improve customers' desires.

For the government, encouraging efficient competitions, maximizing the competition capability and rationalizing resource distribution are rational suggestions. TD-SCDMA needs to be paid special attention to, with its own advantages in frequencies and standards [13].

We haven't made corresponding simulations on government side this time. Modify and making more specific simulations of enterprises' operation behaviors is part of the further work basing on the model.

\section{References}

1. J.D.W Morecroft and J.D. Sterman, Modeling For Learning Organizations (Productive Press, Portland, OR, 1994).

2. T. Perrin, Inside the Balanced Scorecard, Compuscan Report, January, (1996), pp. 3-7.

3. R.S. Kaplan, D.P. Norton, Balanced Scorecard: From Strategy to Application (Harvard Business School Press, 1996)

4. E. Berkman, How to use the Balanced Scorecard (CIO, May 15, 2002)

5. J.W. Forrester, Industrial Dynamics (The MIT Press, Cambridge Massachusetts, 1961)

6. R.S. Kaplan and D.P. Norton, Balanced Scorecard, From Strategy to Application (Harvard Business Review, Boston, 1992) 
7. C.W. Kerkwood, System Dynamics Methods, Version 1, 4/1/1998, pp. 2-16

8. Derivatives Markets Quarterly Report, Hong Kong Exchanges Corporate (1999-2005); http:/ www.hkex.com.hk/ listedco/ listconews/ sehk/

9. R.N. Jia and R.H. Ding, System Dynamics Feedback and Trends' Analysis (Higher Education Press, Beijing, 2002), pp. 35-160.

10. F.R. David, Strategy Management (Economic and Science Press, Beijing, 1989), pp. 5289.

11. Logistics Center, FAA Logistic Center strategic Plan 2003-2007, p. 3; http://www.balancedscorecard.org/(2003)

12. B.F Zhang, Econometrics (Science And Economy Press, Beijing, 1990), pp. 26-82

13. TD-SCDMA, CDMA and 3G, (May, 2005); http://www.tdscdma-alliance.org/

14. R.Z.Yang, Marketing of Current Telecom Enterprises (BUPT press, Beijing, 2003), pp . 50-130

15. Sunzi Tactic in Business Market (January 7, 2006); http://www.hexun.com

16. C.D. Ittner, D.F. Lacker, and M.W. Mayer, Performance Compensation and the Balanced Scorecard (Knowledge at Wharton, November 1, 1997), pp. 25-29.

Appendix

Table1. Simulation data

\begin{tabular}{|c|c|c|c|c|c|c|c|}
\hline Unit (million) & Carrier & & & & & & \\
\hline Year & Income & $\begin{array}{l}\text { Expenses } \\
\text { and costs }\end{array}$ & $\begin{array}{l}\text { Taxes\& } \\
\text { Interests }\end{array}$ & $\begin{array}{l}\text { Net } \\
\text { Profits }\end{array}$ & Dividends & Assets & $\begin{array}{l}\text { Net } \\
\text { Assets }\end{array}$ \\
\hline First Half of 1999 & 16,940 & & & 4,004 & & & \\
\hline Second half of 1999 & 21,683 & & & 793 & & & \\
\hline 1999 & 38,623 & & & 4,797 & & & 65,733 \\
\hline First Half of 2000 & 28,897 & 16,092 & 4,081 & 8,724 & & & 74,457 \\
\hline Second half of 2000 & 36,087 & 40,526 & 4,285 & 9,303 & & & 83,760 \\
\hline 2000 & 64,984 & 56,618 & 8,366 & 18,027 & & & 83,760 \\
\hline First Half of 2001 & 48,864 & 28,146 & 6,909 & 13,809 & 2 & 13,811 & 97,571 \\
\hline Second half of 2001 & 51,467 & 30,467 & 6,794 & 14,206 & 2 & 14,208 & 111,779 \\
\hline 2001 & 100,331 & 58,613 & 13,703 & 28,015 & 4 & 28,019 & 111,779 \\
\hline First Half of 2002 & 55,146 & 32,131 & 7,800 & 15,215 & 5,969 & 21,184 & 132,963 \\
\hline Second half of 2002 & 73,415 & 47,454 & 8,575 & 17,386 & 22,916 & 40,302 & 173,265 \\
\hline 2002 & 128,561 & 79,585 & 16,375 & 32,601 & 28,885 & 61,486 & 173,265 \\
\hline First Half of 2003 & 76,675 & 49,858 & 9,355 & 17,462 & $-6,672$ & 10,79 & 184,055 \\
\hline Second half of 2003 & 81,929 & 55,778 & 8,057 & 18,094 & $-3,346$ & 14,748 & 198,803 \\
\hline 2003 & 158,604 & 105,636 & 17,412 & 35,556 & $-10,018$ & 25,538 & 198,803 \\
\hline First Half of 2004 & 86,420 & 58,232 & 9,359 & 18,829 & $-4,167$ & 14,662 & 213,465 \\
\hline Second half of 2004 & 105,961 & 72,965 & 9,821 & 23,175 & $-3,236$ & 19,939 & 233,404 \\
\hline 2004 & 192,381 & 131,197 & 19,180 & 42,004 & $-7,403$ & 34,601 & 233,404 \\
\hline
\end{tabular}




\begin{tabular}{|c|c|c|c|c|c|c|c|}
\hline Unit (million) & \multicolumn{7}{|c|}{ Carrier B } \\
\hline Year & \multicolumn{7}{|l|}{ Income } \\
\hline First Half of 1999 & \multicolumn{7}{|c|}{8,074} \\
\hline Second half of 1999 & \multicolumn{7}{|c|}{9,376} \\
\hline 1999 & 17,450 & $\begin{array}{l}\text { Expenses } \\
\text { and costs }\end{array}$ & $\begin{array}{l}\text { Taxes\& } \\
\text { Interests }\end{array}$ & $\begin{array}{l}\text { Net } \\
\text { Profits }\end{array}$ & Dividends & Assets & $\begin{array}{l}\text { Net } \\
\text { Assets }\end{array}$ \\
\hline First Half of 2000 & 10,505 & & 360 & 270 & & & \\
\hline Second half of 2000 & 13,187 & & & 569 & & & 8,538 \\
\hline 2000 & 23,692 & & & 839 & & & 8,538 \\
\hline First Half of 2001 & 13,619 & 10,223 & 111 & 171 & & & \\
\hline Second half of 2001 & 15,774 & 9,130 & 994 & 3,063 & & & 57,224 \\
\hline 2001 & 29,393 & 19,353 & 1,105 & 3,234 & 45,452 & 48,686 & 57,224 \\
\hline First Half of 2002 & 17,991 & 10,576 & 851 & 2,192 & & & \\
\hline Second half of 2002 & 22,586 & 13,319 & 190 & 2,265 & & & 61,681 \\
\hline 2002 & 40,577 & 23,895 & 1,041 & 4,457 & 0 & 4,457 & 61,681 \\
\hline First Half of 2003 & 31,967 & 15,125 & 729 & 2,137 & 115 & 2,252 & 63,933 \\
\hline Second half of 2003 & 35,669 & 19,134 & 991 & 2,461 & 259 & 2,720 & 66,653 \\
\hline 2003 & 67,636 & 34,259 & 1,720 & 4,598 & 374 & 4,972 & 66,653 \\
\hline First Half of 2004 & 39,372 & 28,616 & 966 & 2,385 & $-1,256$ & 1,129 & 67,782 \\
\hline Second half of 2004 & 39,960 & 35,669 & 922 & 1,822 & 36,327 & 38,149 & 105,931 \\
\hline 2004 & 79,332 & 73,415 & 1,888 & 4,207 & 35,071 & 39,278 & 105,931 \\
\hline First Half of 2005 & 43,244 & 35,220 & 1,262 & 2,890 & $-6,628$ & $-3,738$ & 102,193 \\
\hline
\end{tabular}

